\title{
Gas-Phase Structure of Protonated Histidine and Histidine Methyl Ester: Combined Experimental Mass Spectrometry and Theoretical ab Initio Study
}

\author{
Borislav Kovačević, Marko Rožman, Leo Klasinc, Dunja Srzić, Zvonimir B. Maksić and Manuel \\ Yáñez
}

Quantum Organic Chemistry Group and Laboratory for Chemical Kinetics and Atmospheric Chemistry, Rudjer Bošković Institute, Bijenička 54, HR-10002 Zagreb, Croatia, and Departamento de Química, C-9, Universidad Autónoma de Madrid, Cantoblanco, 28049-Madrid, Spain

Gas-phase $\mathrm{H} / \mathrm{D}$ exchange experiments with $\mathrm{CD}_{3} \mathrm{OD}$ and $\mathrm{D}_{2} \mathrm{O}$ and quantum chemical ab initio G3(MP2) calculations were carried out on protonated histidine and protonated histidine methyl ester in order to elucidate their bonding and structure. The H/D exchange experiments show that both ions have three equivalent fast hydrogens and one appreciably slower exchangeable hydrogen assigned to the protonated amino group participating in a strong intramolecular hydrogen bond (IHB) with the nearest $\mathrm{N}\left(\mathrm{sp}^{2}\right)$ nitrogen of the imidazole fragment and to the distal ring NH-group, respectively. It is taken for granted that the proton exchange in the IHB is much faster than the H/D exchange. Unlike in other protonated amino acids (glycine, proline, phenylalanine, tyrosine, and tryptophan) studied earlier, the exchange rate of the carboxyl group in protonated histidine is slower than that of the amino group. The most stable conformers and the enthalpies of neutral and protonated histidine and its methyl ester are calculated at the G3(MP2) level of theory. It is shown that strong intramolecular hydrogen bonding between the amino group and the imidazole ring nitrogen sites is responsible for the stability and specific properties of the protonated histidine. It is found that the proton fluctuates between the amino and imidazole groups in the protonated form across an almost vanishing barrier. Proton affinity (PA) of histidine calculated by the G3(MP2) method is 233.2 and $232.4 \mathrm{kcal} \mathrm{mol}^{-1}$ for protonation at the imidazole ring and at the amino group nitrogens, respectively, which is about 3-5 kcal mol${ }^{-1}$ lower than the reported experimental value.

\section{Introduction}

Amino acids are small biomolecules, which provide the principal building blocks for proteins and enzymes. Although most of the chemistry in living organisms takes place in the condensed phase, there has been an increasing interest in the gas-phase structure and conformations of amino acids, peptides, and proteins over the past two decades. ${ }^{1-3}$ This is not surprising, because gas-phase structural investigations of biomolecules provide an important insight into their intrinsic properties free of solvent or crystal phase effects. Another advantage is that the problem of the spatial structure and properties of biomolecules in the gas phase can be addressed by experimental and theoretical methods in a synergistic way.

Emergence of "soft" ionization techniques, such as matrixassisted laser desorption ionization (MALDI) ${ }^{4}$ and electrospray ionization (ESI), ${ }^{5}$ has made gas-phase studies of biomolecules by mass spectrometry widely accepted and utilized. Some other methods, for example, gas-phase hydrogen/deuterium exchange, offer an additional vehicle for structural investigations. ${ }^{6}$ The gas-phase $\mathrm{H} / \mathrm{D}$ exchange studies may give relative exchange rates for different reaction sites, ${ }^{6-8}$ location of the charge, ${ }^{7,8}$ and dependence on the deuterating agent. ${ }^{6,8}$
Histidine is one of the 20 naturally occurring $\alpha$-amino acids. It serves inter alia as a precursor of the hormone histamine, and it regulates the proper utilization of the trace metals and is essential in their rapid excretion, if they were present in excessive amounts. ${ }^{9}$ It is commonly accepted that histidine possesses a pronounced basic character due to its imidazole side chain. Hence, the latter is expected to be the protonation site in multiply protonated proteins. ${ }^{10}$ Furthermore, histidine forms hydrogen bonds acting both as HB donor and as HB acceptor, thus functioning as a proton-transfer mediator in various proteins. ${ }^{11}$ It was argued that imidazole ring forms strong lowbarrier hydrogen bonds (LBHB), known also as SpeakmanHadži H-bonds, ${ }^{12,13}$ which contribute to lowering the transitionstate energy in enzymatic reactions. ${ }^{14,15}$ Although this hypothesis has been challenged by several researchers, ${ }^{16,17}$ additional investigations are highly desirable. A recent study of hydrogen bonding in a complex of serine with histidine, performed by computational and spectroscopic methods on some model compounds, is a step in this direction. ${ }^{18}$

There are only a few studies (theoretical and H/D exchange) on the structure of protonated histidine to the best of our knowledge. ${ }^{10,19,20}$ Green and Lebrilla ${ }^{10}$ performed a gas-phase $\mathrm{H} / \mathrm{D}$ exchange experiment on protonated histidine with $\mathrm{CH}_{3}-$ OD as deuterating agent. Site-independent treatment indicated that there was one slowly exchanging and four equivalent fastexchanging protons. A combination of the semiempirical AM1, MNDO/M and PM3 and ab initio methods carried out by Schaefer and co-workers ${ }^{19}$ has led to the conclusion that PA of 
His is $232.7 \mathrm{kcal} \mathrm{mol},{ }^{-1}$ whereas the subsequent MP2(fc)/6$311+\mathrm{G}^{* *} / / \mathrm{HF} / 6-31 \mathrm{G}^{*}$ calculations gave $229.8 \mathrm{kcal} / \mathrm{mol}{ }^{20}$ This latter estimate was in good accordance with the earlier kinetic measurements of Bojesen and Breindahl, ${ }^{21}$ but it was about 6 $\mathrm{kcal} \mathrm{mol}^{-1}$ too low according to the thermokinetic method of Bouchoux and Salpin ${ }^{22,23}$ and compared to the value of 236 kcal $\mathrm{mol}^{-1}$ adopted by Hunter and Lias. ${ }^{24}$

It is the aim of the present work to shed more light on the gas-phase structure of protonated histidine by combining results of the H/D exchange reactions of protonated histidine in the gas phase with those of electronic structure calculations obtained at the G3(MP2) level of theory. Particular attention will be focused on the determination of the most basic site of His, which is of great importance for a better understanding of its biological activity.

\section{Materials and Methods}

Experimental Methods. The H/D exchange experiments were performed in a $3 \mathrm{~T}$ Fourier transform ion cyclotron resonance (FTICR) mass spectrometer with a Nicolet 1280 data station (Extrel FTMS 2001, Madison, WI) equipped with a nitrogen laser (VSL 337 NSD, LSI Laser Science, Newton, MA) emitting at $\lambda=337 \mathrm{~nm}$. Histidine (His) and histidine methyl ester (HisOMe) were obtained from Fluka (Buchs, Switzerland). The deuteration reagent $\mathrm{D}_{2} \mathrm{O}(99.8 \%)$ and $\mathrm{CD}_{3} \mathrm{OD}(99.8 \%)$ were obtained from Aldrich (Milwaukee, WI) and from Cambridge Isotope Laboratories (Andover, MA), respectively. Ions were formed by MALDI from samples prepared by a standard drieddroplet procedure with 2,5-dihydroxybenzoic acid (DHB) as matrix. Strongest ion signals were obtained with a sample-tomatrix ratio of $\sim 1: 100$. Before each experiment, deuterating gas was introduced for several hours directly into the ICR cell for stabilization. Reagent gas pressure used in the exchange experiments was $(6.5-1.33) \times 10^{-5} \mathrm{~Pa}$ and it was measured with a Bayard-Alpert-type ionization gauge with parametrized response factors for calibration. ${ }^{25}$ All experiments were carried out at room temperature of $300 \mathrm{~K}$. H/D exchange experiments were performed according to the procedure mentioned in an earlier publication. ${ }^{8}$

Data obtained from mass spectra consist of relative intensities of the mass peaks for $\mathrm{D}_{0}, \mathrm{D}_{1}, \ldots, \mathrm{D}_{n}$ (where $\mathrm{D}_{n}$ represents an ion species containing a total of $n$ deuterium atoms) measured at a number of time points that correspond to different time delays for the exchange reaction. The kinetic system is treated as $n$ independent exchangeable hydrogen atoms each following a simple pseudo-first-order rate law. With this approach we determined the site-specific rate constants of the studied protonated amino acids. An interactive program for calculation of the site-specific rate constants was written in Mathematica 4.0 (Wolfram Research, Champaign, IL). Repetitive H/D exchange experiments indicate a relative standard deviation of $20 \%$ for the reported site-specific rate constants. Assuming that ion gauges are properly calibrated, the major sources of error in the numerical values of the site-specific rate constants are the pressure measurements. It is worth mentioning that the ratios between the rates of exchange for the sites in each experiment remain unaffected by the number of experimental runs.

Theoretical and Computational Methods. Ab initio MO calculations were performed by the GAUSSIAN $98^{26}$ program package. Initial search of minima on the potential energy (hyper)surface (PES) were carried out by the density functional $(\text { DFT })^{27}$ method using B3LYP functional ${ }^{28,29}$ employing 6-31G* basis set. For the true minima on the PES corresponding to most stable conformers, the G3(MP2) structures and energies are

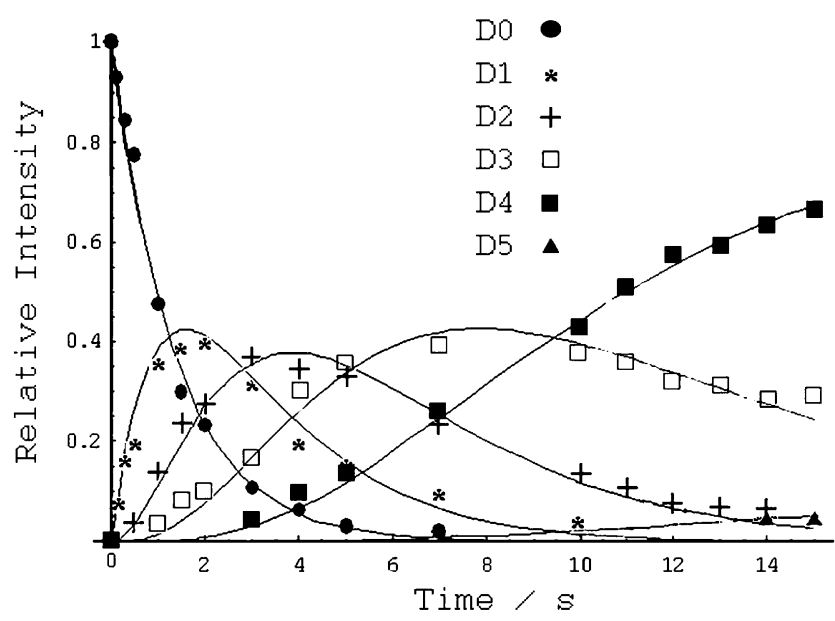

Figure 1. Time dependence of the experimental ion intensities and the corresponding theoretical fits obtained with site-specific treatment in the $\mathrm{H} / \mathrm{D}$ exchange reaction of the $\mathrm{HisH}^{+}$with $\mathrm{D}_{2} \mathrm{O}$. The least-squares sum (LSS) for this fit is 0.037 .

calculated, because this theoretical model provides thermodynamic data (including proton affinities) ${ }^{30}$ with acceptable accuracy. The relevant formulas for calculating the absolute proton affinities APAs in the gas phase are given by

$$
\begin{gathered}
\operatorname{APA}\left(\mathrm{B}_{\alpha}\right)=\left(\Delta E_{\mathrm{el}}\right)_{\alpha}+\left(\Delta E_{\mathrm{vib}}\right)_{\alpha}+(5 / 2) R T \\
\left(\Delta E_{\mathrm{el}}\right)_{\alpha}=E(\mathrm{~B})-E\left(\mathrm{~B}_{\alpha} \mathrm{H}\right)^{+} \\
\left(\Delta E_{\mathrm{vib}}\right)_{\alpha}=E_{\mathrm{vib}}(\mathrm{B})-E_{\mathrm{vib}}\left(\mathrm{B}_{\alpha} \mathrm{H}\right)^{+}
\end{gathered}
$$

The base and its conjugate acid are denoted by $\mathrm{B}$ and $\mathrm{BH}^{+}$, respectively, whereas $\alpha$ stands for the site of proton attack. The term $\left(\Delta E_{\mathrm{el}}\right)_{\alpha}$ is the electronic contribution to proton affinity, $E_{\text {vib }}$ includes the zero-point vibrational energy (ZPVE) and temperature corrections to the vibrational enthalpy, and $(5 / 2) R T$ includes the translational energy of the proton, and the pressurevolume work term. In the standard G3 procedure, vibrational frequencies are evaluated at the HF level within the harmonic approximation. Although this approximation is not adequate for the treatment of such highly anharmonic vibrations as some of those occurring in intramolecular hydrogen bonds, its effect on the ZPVE and on the vibrational shiftings discussed in this paper is rather small.

\section{Results and Discussion}

Histidine. The gas-phase protonated His studied in this work was produced by MALDI, which typically generates protonated gas-phase ions. $\mathrm{HisH}^{+}$was reacted with $\mathrm{CD}_{3} \mathrm{OD}$ and $\mathrm{D}_{2} \mathrm{O}$ compounds in the gas phase, and the site-specific rate constants for the H/D exchange were determined. Results obtained with $\mathrm{CD}_{3} \mathrm{OD}$ as deuterating reagent show qualitatively the same pattern as with $\mathrm{D}_{2} \mathrm{O}$. Figure 1 shows the time dependence of the normalized intensities of protonated histidine in a reaction with $\mathrm{D}_{2} \mathrm{O}$. Incorporation of the fifth deuterium was very slow and the corresponding signal in the spectrum had a very low relative intensity even at maximum reaction time delay, which was limited by the instrument performance. Because of a decreasing signal with time, the calculated rate constant for the last proton exchange has the highest error. The site-specific gasphase $\mathrm{H} / \mathrm{D}$ exchange rate constants obtained for $\mathrm{HisH}^{+}$are presented in Table 1. The first observation to be made is that discrimination between the different $\mathrm{H} / \mathrm{D}$ exchange sites is much 
TABLE 1: Site-specific Gas Phase H/D Exchange Rate Constants $^{a}$ for Studied $\mathrm{HisH}^{+}$with $\mathrm{CD}_{3} \mathrm{OD}$ and $\mathrm{D}_{2} \mathrm{O}$

\begin{tabular}{ccc}
\hline $\mathrm{HisH}^{+}$ & $\mathrm{CD}_{3} \mathrm{OD}$ & $\mathrm{D}_{2} \mathrm{O}$ \\
\hline$k_{1}$ & 44.95 & 11.63 \\
$k_{2}$ & 44.95 & 11.63 \\
$k_{3}$ & 44.95 & 11.63 \\
$k_{4}$ & 23.5 & 6.53 \\
$k_{5}$ & 1.02 & 0.29
\end{tabular}

${ }^{a}$ Rate constants $\left(k_{\mathrm{i}} \pm 20 \%\right)$ are given in units $\times 10^{-12}$ cubic centimeter per second per molecule.

more pronounced in the $\mathrm{CD}_{3} \mathrm{OD}$ experiments, particularly if the rather large experimental error of $\pm 20 \%$ is taken into account.

The site-specific treatment of $\mathrm{H} / \mathrm{D}$ exchange in $\mathrm{HisH}^{+}$with $\mathrm{CD}_{3} \mathrm{OD}$ and $\mathrm{D}_{2} \mathrm{O}$ indicates four relatively fast-exchanging and one very slowly exchanging site. Three of the four fastexchanging sites are equivalent, implying an equivalency of hydrogens in the protonated amino group of $\mathrm{HisH}^{+}$. Consequently, the $\mathrm{OH}$ of the carboxylic group and the $\mathrm{NH}$ of the imidazole ring are sites that undergo a fast and a very slow H/D exchange. They will be distinguished by additional experiments (vide infra). As already mentioned, previous analyses ${ }^{10}$ of the same system indicated four equivalent and fastexchanging hydrogens together with the one slowly exchanging $\mathrm{H}$ atom. This result was explained by a bridging interaction between the $\alpha$-amino group and the imidazole ring. When the distances between the imidazole ring nitrogen atoms and the $\alpha$-amino group as well as the proposed bridging interaction are taken into account, this implies a continuous change in the site of protonation and bridging, which is not very likely. It should be noted in this regard that the site-specific rate constants for $\mathrm{HisH}^{+}$had the highest estimated error in the fit (LSS value) of all species in the work of Green and Lebrilla. ${ }^{10}$
TABLE 2: G3(MP2) Enthalpies $H^{298}$ and Relative Stabilities $\Delta$ of Conformers/Tautomers of Neutral and Protonated Histidine $^{a}$

\begin{tabular}{lll}
\hline & $H^{298}$ & $\mathrm{D}$ \\
\hline His(a) & -547.98058 & 0.0 \\
His(b) & -547.97760 & 1.9 \\
His(c) & -547.97609 & 2.8 \\
His(d) & -547.97519 & 3.4 \\
$\mathrm{HisH}^{+}(\mathrm{a})$ & -548.34988 & 0.0 \\
$\mathrm{HisH}^{+}(\mathrm{b})$ & -548.34495 & 3.1 \\
$\mathrm{HisH}^{+}(\mathrm{c})$ & -548.34853 & 0.8 \\
$\mathrm{HisH}^{+}(\mathrm{TS})$ & -548.34817 & 1.1
\end{tabular}

${ }^{a}$ Enthalpies are given in a.u.; relative stabilities are given in kilocalories per mole.

To find the most stable conformations of His/HisH ${ }^{+}$and to assign the exchangeable proton sites, we undertook a series of $\mathrm{ab}$ initio calculations. The most stable tautomers and conformers of neutral and protonated histidine are shown in Figure 2. The corresponding G3(MP2) enthalpies and relative stabilities of tautomers and conformers are given in Table 2.

The imidazole group of the histidine side chain possesses two possible tautomeric forms in neutral molecule. It can serve as a proton donor and/or proton acceptor moiety in intramolecular (IHB) and intermolecular hydrogen-bond formation. The same holds for the amino and carboxylic functional groups. Consequently, it follows that there are many possible ways to form intramolecular hydrogen bonds, which can stabilize both neutral and protonated histidine species. The most stable structure has two intramolecular hydrogen bonds, one between the carbonyl oxygen and the imidazole hydrogen and the other between the hydroxyl oxygen and the amino nitrogen lone pair. It is interesting to mention that Schaefer and co-workers ${ }^{19}$ predicted the structure His(b) as a global minimum on the basis

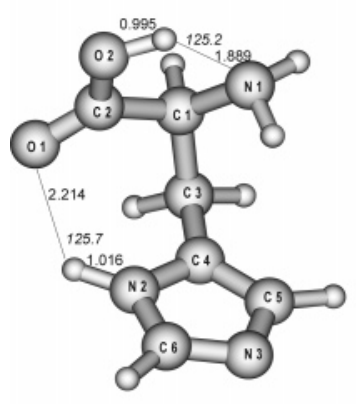

His(a)

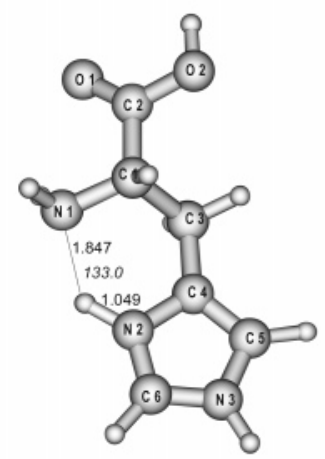

$\operatorname{HisH}^{+}(\mathrm{a})$

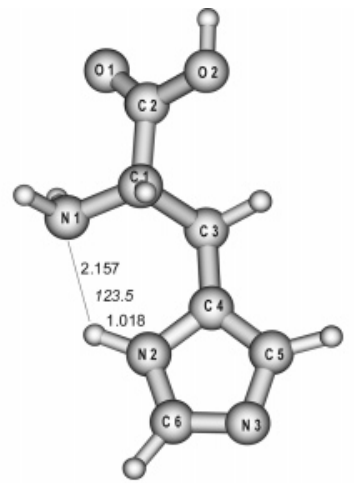

$\operatorname{His}(\mathrm{b})$

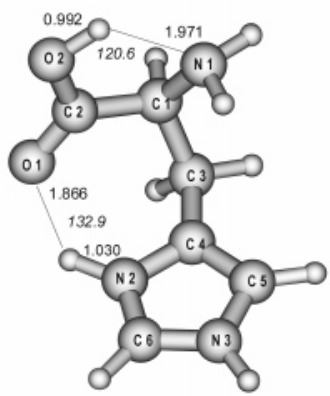

$\operatorname{HisH}^{+}(b)$

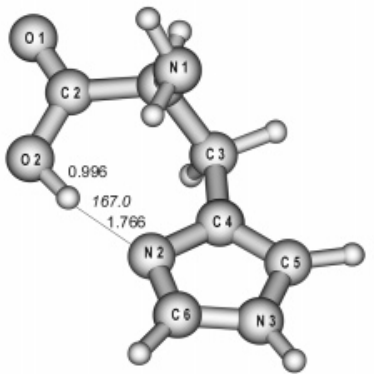

His(c)

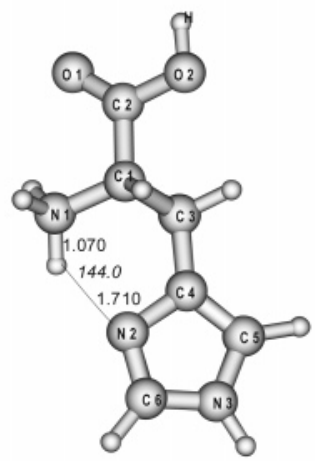

$\mathrm{HisH}^{+}$(c)

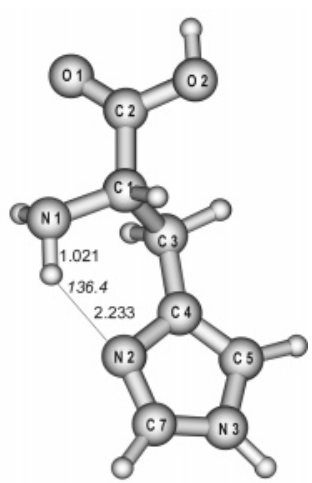

His(d)

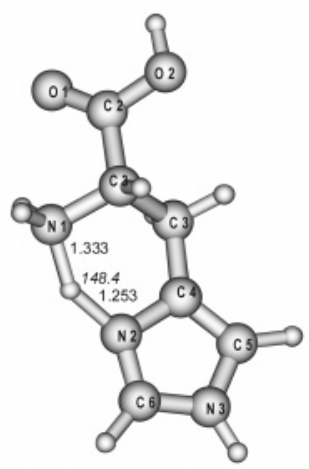

$\mathrm{HisH}^{+}(\mathrm{TS})$

Figure 2. Most stable conformers/tautomers of neutral and protonated histidine as obtained by the MP2(fu)/6-31G* models. The most relevant distances and angles (shown in italic type) pertaining to the structural features of the IHBs are given in angstroms and degrees, respectively. 
of semiempirical AM1, PM3, and MNDO calculations. However, semiempirical schemes are not quite reliable, because they are unable to offer an adequate description of the HBs. It is well-known, for example, that the MNDO method underestimates hydrogen-bond energy by $50 \%$ or more, especially if the hydrogen bridge is not linear like the IHB in histidine. It is important to notice, however, that the ab initio energy differences among His(a)-His(d) tautomers and conformers are small and do not exceed $3.2 \mathrm{kcal} \mathrm{mol}^{-1}$ in total (Table 2). In particular, the conformer His(b) is less stable than His(a) by only $1.9 \mathrm{kcal}$ $\mathrm{mol}^{-1}$. We believe that the G3(MP2) computational protocol gives results accurate enough to yield a correct hierarchy in stability of His and its tautomers and conformers. It is expected that the same holds for their protonated forms. We note in passing that the G2(MP2) method yields quite similar results (vide infra).

Protonation of His(a) at the $\mathrm{sp}^{2}$-nitrogen atom of the imidazole ring gives structure $\mathrm{HisH}^{+}(\mathrm{b})$, but this conformer is not the global minimum on the PES. The latter is obtained by protonation of His(b), leading to the $\mathrm{HisH}^{+}$(a) form (Figure 2) with a short and strong hydrogen bond between proton at the imidazole ring and the lone pair of the amino group. The distance between the imidazole ring nitrogen and the amino nitrogen atom is relatively short (2.675 $\AA$ ). Therefore, it is plausible to assume that proton transfer occurs from the imidazole to the amino group, yielding structure $\mathrm{HisH}^{+}(\mathrm{c})$. Indeed, the energy difference between these two prototropic tautomers is very small $\left(0.8 \mathrm{kcal} \mathrm{mol}^{-1}\right)$. Moreover, it is quite conceivable that this proton shuttles between $\mathrm{N}\left(\mathrm{sp}^{3}\right)$ and $\mathrm{N}\left(\mathrm{sp}^{2}\right)$ atoms, since the barrier height is also very low $\left[1.1 \mathrm{kcal} \mathrm{mol}^{-1}\right.$ above $\mathrm{HisH}^{+}$(a) and $0.3 \mathrm{kcal} \mathrm{mol}^{-1}$ above $\mathrm{HisH}^{+}(\mathrm{c})$ ], allowing for an almost free proton transfer and rapidly interconverting tautomers (Table 2). This would explain the three equivalent $\mathrm{H} / \mathrm{D}$ exchanges observed in the present study taking place at the $\mathrm{NH}_{2}$ group in the $\mathrm{HisH}^{+}$(a) protonated form. The main features of the proton transfer will be discussed in more detail later.

Let us now focus on the proton affinity (PA) of histidine. For this purpose we shall consider first the most stable tautomer in its preferred conformation, His(a), and monitor what happens upon protonation of the imino nitrogen of the imidazole ring. The reaction His(a) $+\mathrm{H}^{+} \rightarrow \mathrm{HisH}^{+}$(a) PA of $233.2 \mathrm{kcal} \mathrm{mol}^{-1}$, which is too low by $3 \mathrm{kcal} \mathrm{mol}^{-1}$ according to the experimental value of $236 \mathrm{kcal} \mathrm{mol}^{-121}$ obtained by thermokinetic methods. ${ }^{22,23}$ The earlier value listed by Hunter and Lias ${ }^{24}$ was also $236 \mathrm{kcal} \mathrm{mol}^{-1}$. Our additional G2(MP2) calculations yield PA $=232.9 \mathrm{kcal} \mathrm{mol}^{-1}$. The most recent results of Bouchoux et al. ${ }^{3}$ by the extended kinetic method with the "isothermal point" and protonation entropy $\Delta_{\mathrm{p}} S^{\circ}=-2.6 \mathrm{kcal} \mathrm{mol}^{-1} \mathrm{read} 238.0 \pm$ $1.4 \mathrm{kcal} \mathrm{mol}^{-1}$, thus being higher than all other measured values. Previous MP2(fc)/6-311+G**//HF/6-31G* + ZPVE(HF/6$31 \mathrm{G}^{*}$ ) and the scaled $\mathrm{HF}$ calculations gave the PA values of 229.8 and $230.5 \mathrm{kcal} \mathrm{mol}^{-1}$, respectively. ${ }^{20} \mathrm{Hence}$, discrepancy between theory and experiment is at least $3 \mathrm{kcal} \mathrm{mol}^{-1}$, unless one adopts the PA reported by Harrison ${ }^{1}$ as the most reliable one. It is $234.5 \mathrm{kcal} \mathrm{mol}^{-1}$, which was obtained by the assumption that entropy $\Delta S_{\text {rot }}^{\circ}=-10 \mathrm{cal} \mathrm{mol}^{-1} \mathrm{~K}^{-1}$. At first sight it seems that a better agreement with experiment could be obtained by taking into account all tautomers and conformers and treating them as an ensemble following a Boltzmann distribution of species and energies. However, it was shown by Sun et al., ${ }^{31}$ by considering glutamic acid, that Boltzmann averaging is approximate and that it could introduce significant error into theoretical PA value. Concomitantly, we did not proceed in this direction.

A surprising finding is that both PAs of imidazole ring and amino group are almost the same in histidine, because it is wellknown ${ }^{24}$ that primary amines are significantly less basic than imidazoles in the gas phase. An explanation is offered by different intramolecular hydrogen-bond strengths in structures $\mathrm{HisH}^{+}$(a) and $\mathrm{HisH}^{+}(\mathrm{c})$. For this purpose it is useful to consider the topology of their charge density, ${ }^{32}$ the lengthening of the $\mathrm{HB}$ donor bond, and the red shift of its stretching frequency, since all these indices provide indirect but indicative information on the relative stabilization associated with the inter- and intramolecular HBs. The bond critical points (bcp) associated with the $\mathrm{HBs}$ in $\mathrm{HisH}^{+}$(a) and $\mathrm{HisH}^{+}$(c) were located, and it appeared that the value of the charge density at the $\mathrm{N}(2)-\mathrm{H} \cdots$ $\mathrm{N}(1) \mathrm{HB}$ in $\mathrm{HisH}^{+}$(a) (0.040 au) was indeed lower than that at the $\mathrm{N}(1)-\mathrm{H} \cdots \mathrm{N}(2) \mathrm{HB}$ (bcp) in $\mathrm{HisH}^{+}(\mathrm{c})$ (0.050 au). In addition, the charge density at the corresponding ring critical point, which is also a good measure of the strength of intramolecular interactions, ${ }^{33}$ is also slightly larger $(0.016 \mathrm{au})$ for the latter hydrogen bond compared to the former one $(0.014$ au). Similarly, the stretching frequency of the $\mathrm{N}(2)-\mathrm{H}$ donor in $\mathrm{HisH}^{+}$(a) is red-shifted by $182 \mathrm{~cm}^{-1}$ with respect to the other $\mathrm{N}(3) \mathrm{H}$ bond of the imidazole ring not participating in the HB. Analogously, in $\mathrm{HiSH}^{+}$(c) the stretching frequency of the $\mathrm{N}(1) \mathrm{H}$ bond involved in the $\mathrm{HB}$ is red-shifted by $425 \mathrm{~cm}^{-1}$ relative to the stretching frequencies of the other two $\mathrm{N}(1) \mathrm{H}$ bonds. Although the stretching frequencies were calculated in a standard way, without taking into account anharmonicities, it is expected that thay are qualitatively correct. This is sufficient for comparative purposes. Finally, the $\mathrm{N}(1) \mathrm{H}$ bond of $\mathrm{HisH}^{+}(\mathrm{c})$ involved in the $\mathrm{HB}$ is $0.048 \AA$ longer than the other two $\mathrm{N}(1) \mathrm{H}$ bonds, whereas the lengthening of the $\mathrm{N}(2) \mathrm{H}$ bond of $\mathrm{HisH}^{+}(\mathrm{a})$ with respect to the other $\mathrm{N}-\mathrm{H}$ bond of the azolic ring is $0.031 \AA$. Hence, all indices indicate that the $\mathrm{N}(1)-\mathrm{H} \cdots \mathrm{N}(2)$ IHB in $\mathrm{HisH}^{+}(\mathrm{c})$ is much stronger than the $\mathrm{N}(2)-\mathrm{H} \cdots \mathrm{N}(1)$ one in $\mathrm{HisH}^{+}(\mathrm{a})$.

This qualitative information could be put in some more quantitative results by using the concept of homodesmotic reactions. $^{34}$ It was shown by Howard ${ }^{35}$ that isodesmic and homodesmotic reactions are useful in estimating the strengths of IHBs. Let us consider the gedanken reactions (4) and (5).

The G3(MP2) model yields $\Delta E(1)=7.5 \mathrm{kcal} \mathrm{mol}^{-1}$ and $\Delta E(2)=21.0 \mathrm{kcal} \mathrm{mol}^{-1}$, implying that the protonated $\mathrm{NH}_{2}$ group is a better donor of the IHB, whereas the $\mathrm{N}\left(\mathrm{sp}^{2}\right)$ atom of the imidazole ring is a better acceptor of the IHB than vice versa. The difference in the stabilization energy of these two types of IHBs is appreciable $\left(13.5 \mathrm{kcal} \mathrm{mol}^{-1}\right)$.

In view of the pivotal role of IHBs in general and for $\alpha$-amino acids and peptides in particular, we decided to explore an open hydrogen bond between the simple model compounds 5-methylimidazole and methylamine (Figure 3 ). Although the linear HBs occurring between free model molecules are different from cyclic ones taking place in His, some general features should be the same. This is of importance, since a detailed and quantitative quantum description of IHB in His would be too demanding.

Proton affinities of methylamine and 5-methylimidazole obtained by G3(MP2) method are 215.5 and $230.1 \mathrm{kcal} \mathrm{mol}^{-1}$, respectively, implying that the imino nitrogen in 5-methylimidazole is intrinsically more basic as evidenced by its higher predicted PA by $14.6 \mathrm{kcal} \mathrm{mol}^{-1}$. The corresponding experimental values are 214.9 and $227 \mathrm{kcal} \mathrm{mol}^{-1} \cdot{ }^{24}$ It is interesting to note that full G2 calculation of PA in 5-methylimidazole gives 

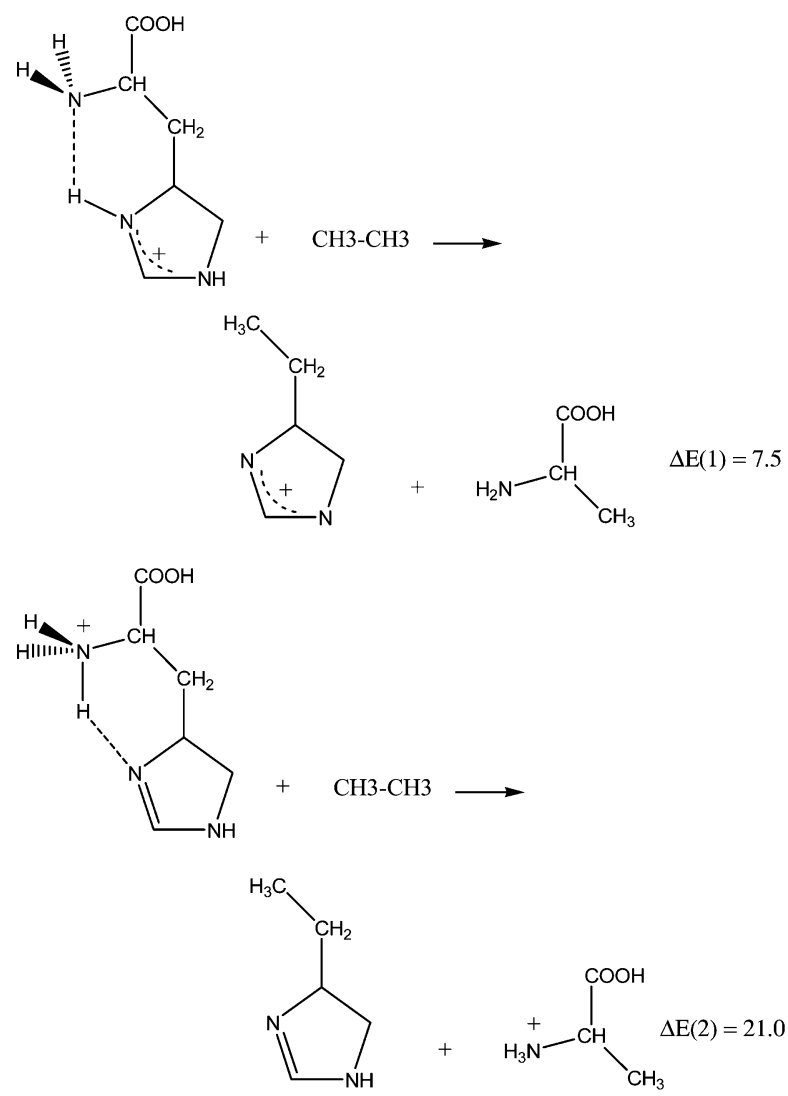

$229.9 \mathrm{kcal} \mathrm{mol}^{-1}$, thus lending strong support to the G3(MP2) result. Consequently, additional experimental measurements of PA of the 5-methylimidazole are well advised, since the experimental value is $3 \mathrm{kcal} \mathrm{mol}^{-1}$ too low. The hydrogen-bond strength of dimers I and II is of importance. It can be calculated as a difference between the energy of dimers and the sum of energies of isolated neutral and protonated methylamine and 5-methylimidazole. It should be mentioned in this context that geometries of both free model compounds and their complexes were fully optimized. The resulting hydrogen-bond strengths of complexes I and II are 19.4 and $32.3 \mathrm{kcal} \mathrm{mol}^{-1}$, respectively. The basis-set superposition errors (BSSE) were not considered, because the G3(MP2) method uses very large and flexible basis sets. Hence BSSE is expected to be negligible. In other words, the IHB strength in dimer II is larger by $12.9 \mathrm{kcal} \mathrm{mol}^{-1}$, since the quaternary nitrogen cation $\mathrm{MeNH}_{3}{ }^{+}$is a better $\mathrm{H}$-bond donor and the imino $\mathrm{N}\left(\mathrm{sp}^{2}\right)$ atom is a better $\mathrm{H}$-bond acceptor than the other way around. Upon comparison of these results with previous ones deduced from homodesmotic reactions 4 and 5, it appears that the absolute values of the IHB strengths are higher for the open linear hydrogen bond, but the difference between the two modes of H-bonding is practically the same (12.9 vs $\left.13.5 \mathrm{kcal} \mathrm{mol}^{-1}\right)$ ! It follows that practically the same susceptibility toward protonation of the amino and imino nitrogen atoms is accidental, being a consequence of a considerably stronger $\mathrm{H}$-bond formed by the quaternary cationic $\mathrm{N}$ atom and the $\mathrm{N}\left(\mathrm{sp}^{2}\right)$ lone pair of the imidazole ring. The most important result is a finding that protonation of the $\alpha$-amino group is almost as important as protonation of the imidazole ring. In both cases, however, the azole ring plays a very important role.

The potential energy curve for a possible proton transfer between the model molecules 5-methylimidazole and methylamine is also of interest. The energy profile is computed by MP2(full)/6-31+G** employing the "shooting method" in solving a one-dimensional Schrödinger equation involving anharmonic potential. ${ }^{36}$ The total molecular energy was calculated by varying $d(\mathrm{~N}-\mathrm{H})$ distance along the straight line passing through the imine and amine nitrogens within the range 0.9$1.8 \AA$ by using a step of $0.1 \AA$. The patches of the energy curve between two calculated neighboring points are obtained by the cubic spline interpolation. The resulting curve is depicted in Figure 4.

The potential has two slightly unsymmetrical minima separated by a very low barrier, especially when zero-point vibrational energy (ZPVE) of $2.5 \mathrm{kcal} \mathrm{mol}^{-1}$ is taken into account. The barrier is $1.1 \mathrm{kcal} \mathrm{mol}^{-1}$, implying that the proton transfer is almost barrierless. It is virtually the same as the transition structure energy $\mathrm{HisH}^{+}$(TS) relative to His(a) (Table 2 ). The difference in two minima yielding the total molecular energies of the complexes I and II is $2.3 \mathrm{kcal} \mathrm{mol}^{-1}$, thus being compatible with a slightly larger stability of $\mathrm{HisH}^{+}(\mathrm{a})$ relative to $\mathrm{HisH}^{+}(\mathrm{c})$. Although the actual energy profile for intramolecular proton transfer in $\mathrm{HisH}^{+}$is somewhat different than that shown in Figure 4, its shape should be also slightly unsymmetrical, and one can safely conclude that proton moves almost freely from the amino to the imino group without a substantial influence of the barrier.

Histidine Methyl Ester. The H/D exchange in protonated HisOMe was studied in order to (i) assign the exchange at carboxylic and imidazole ring nitrogen sites, (ii) confirm that the three equivalent exchanging sites belong to the $\alpha$-amino group, and (iii) prove that the proposed proton transfer (fluctuation) between the $\alpha$-amino group and the imidazole ring nitrogen indeed occurs. HisOMe has basically the same molecular structure as His itself, with a distinct difference that the carboxyl group is methylated. The same level of ab initio calculations G3(MP2) was used to find the most stable conformations of protonated histidine methyl ester $\left(\mathrm{HiSOMeH}^{+}\right)$(shown in Figure $5)$. It is clear from Table 3 that the energy differences between conformers/tautomers of protonated histidine methyl ester are not only smaller than in the case of histidine, but the hierarchy is slightly changed too. It appears that $\mathrm{HiSOMeH}^{+}(\mathrm{b})$ is more stable than $\mathrm{HiSOMeH}^{+}(\mathrm{a})$, albeit to a very tiny extent $(0.2 \mathrm{kcal}$ $\mathrm{mol}^{-1}$ ). Then, the $\mathrm{H} / \mathrm{D}$ exchange experiments with $\mathrm{CD}_{3} \mathrm{OD}$ and $\mathrm{D}_{2} \mathrm{O}$ on MALDI-generated $\mathrm{HisOMeH}^{+}$were carried out and the site-specific rate constants were determined.

Two approaches were used in interpreting results of the H/D exchange. In the first, the existence of the single most stable conformation $(\mathrm{X})$ was anticipated. Second, the presence of two $\mathrm{HisOMeH}^{+}$gas-phase conformations ( $\mathrm{X}$ and $\mathrm{Y}$ ) was assumed and the kinetic analysis was modified accordingly: the system
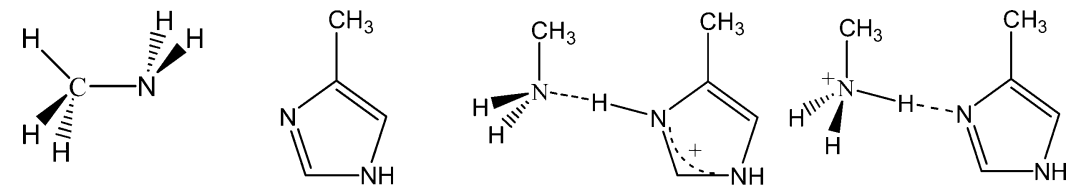

methylamine

5-methylimidazole

dimer I

dimer II

Figure 3. Schematic representation of methylamine and 5-methylimidazole and their protonated dimers. 


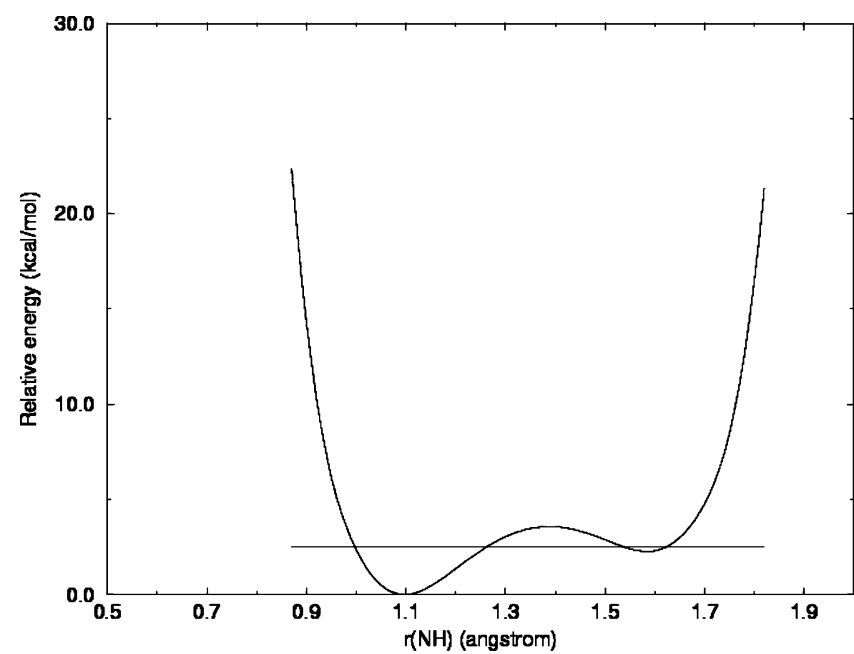

Figure 4. Proton potential in methylamine-5-methylimidazole complex calculated at MP2(full)/6-31+G** level of theory. The lower minimum corresponds to dimer I. The straight line gives the contribution of the ZPVE to the total energy.

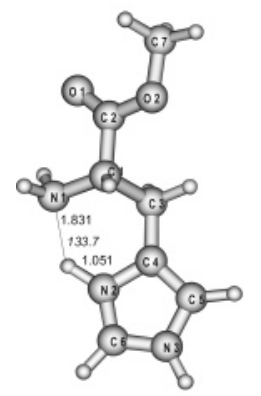

$\mathrm{HisOMeH}^{+}(\mathrm{a})$

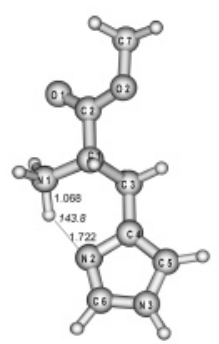

$\mathrm{HisOMeH}^{+}(\mathrm{b})$

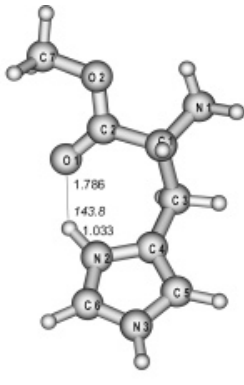

$\mathrm{HisOMeH}^{+}(\mathrm{c})$
Figure 5. Most stable conformers of protonated histidine methyl ester as obtained from the MP2(fu)/6-31G* models. The most relevant distances and angles (shown in italic type) pertaining tothe structural features of the IHBs are given in angstroms and degrees, respectively.

TABLE 3: G3(MP2) Enthalpies $\mathbf{H}^{298}$ and Relative Stabilities $\Delta$ of Conformers of Protonated Histidine Methyl Ester ${ }^{a}$

\begin{tabular}{ccc}
\hline & $H^{298}$ & $\mathrm{D}$ \\
\hline $\mathrm{HisOMeH}^{+}(\mathrm{a})$ & -587.57068 & 0.2 \\
$\mathrm{HisOMeH}^{+}(\mathrm{b})$ & -587.57096 & 0.0 \\
$\mathrm{HiSOMeH}^{+}(\mathrm{c})$ & -587.56913 & 1.1
\end{tabular}

${ }^{a}$ Enthalpies are given in a.u.; relative stabilities are given in kilocalories per mole.

was treated as a sum of the two conformations, each with four independent exchangeable sites. Consequently, it is defined by the abundances of $x$ and $y$, corresponding to conformers $\mathrm{X}$ and $\mathrm{Y}, 0 \leq\{x, y\} \leq 1, x+y=1$, respectively. Specifically, concentration of $\mathrm{D}_{0}$ is obtained by adding up the concentration of conformation $\mathrm{X}$ with an abundance $x$ and conformation $\mathrm{Y}$ with an abundance $y$, where $\mathrm{D}_{0}$ denotes the species without deuterium.

Table 4 shows the site-specific gas-phase H/D exchange rate constants for $\mathrm{HiSOMeH}^{+}$and the least-squares deviation sums (LSS) obtained by the fitting procedure. The least (slowest) proton exchange in $\mathrm{HisOMeH}^{+}$has percentagewise the highest experimental error for the same reason as in the parent $\mathrm{HisH}^{+}$.

The first approach (one conformation system) yields for protonated HisOMe three equivalent fast-exchanging and one slowly exchanging site. Comparison with protonated $\mathrm{HisH}^{+}$ shows that the single nonequivalent fast-exchanging site attributed to the carboxylic group is missing in $\mathrm{HiSOMeH}^{+}$.
TABLE 4: Site-Specific Gas-Phase H/D Exchange Rate Constants $\left(k_{\mathrm{i}} \pm 20 \%\right)$ for Studied HisOMeH ${ }^{+}\left(\times \mathbf{1 0}^{-12}\right.$ $\mathrm{cm}^{3} \mathrm{~s}^{-1} \mathrm{Molecule}^{-1}$ ) with $\mathrm{CD}_{3} \mathrm{OD}$ and $\mathrm{D}_{2} \mathrm{O}$

\begin{tabular}{|c|c|c|c|c|c|c|}
\hline \multirow{3}{*}{$\begin{array}{l}\text { LSS } \\
\end{array}$} & \multicolumn{2}{|c|}{$\begin{array}{c}\text { HisOMeH }^{+} \text {one } \\
\text { conformation system }\end{array}$} & \multicolumn{4}{|c|}{$\begin{array}{l}\text { HisOMeH }{ }^{+} \text {two } \\
\text { conformation system }\end{array}$} \\
\hline & \multirow{3}{*}{$\frac{\mathrm{CD}_{3} \mathrm{OD}}{0.015}$} & \multirow{2}{*}{$\frac{\mathrm{D}_{2} \mathrm{O}}{0.01}$} & \multicolumn{2}{|c|}{$\mathrm{CD}_{3} \mathrm{OD}$} & \multicolumn{2}{|c|}{$\mathrm{D}_{2} \mathrm{O}$} \\
\hline & & & 0.011 & 0.011 & 0.008 & 0.008 \\
\hline conformation & & $\mathrm{X}$ & $\mathrm{X}$ & $\mathrm{Y}$ & $\mathrm{X}$ & Y \\
\hline abundance & & & 0.8 & 0.2 & 0.8 & 0.2 \\
\hline$k_{1}$ & 33.8 & 8.51 & 36.33 & 32.65 & 8.77 & 7.74 \\
\hline$k_{2}$ & 33.8 & 8.51 & 36.33 & 32.65 & 8.77 & 7.74 \\
\hline$k_{3}$ & 33.8 & 8.51 & 36.33 & 17.06 & 8.77 & 4.13 \\
\hline$k_{4}$ & 2.07 & 0.52 & 1.84 & 0.92 & 1.03 & 0.26 \\
\hline
\end{tabular}

Therefore, three equivalent exchanging sites strongly imply that both protonated His and HisOMe have three equivalent hydrogens belonging either to the protonated amino group or to the $\mathrm{NH}_{2}$ groups, with an additional fast-shuttling proton as in the $\mathrm{HisH}^{+}$case. A slowly exchanging site is associated with a distant imidazole nitrogen, which is not involved in $\mathrm{HB}$ with the amino group. The experimental rate constants are thus fully consistent with those observed in the parent $\mathrm{HisH}^{+}$, corroborating earlier contention that the proton transfer takes place between the amino group and the nearest $\mathrm{N}(2)$ atom of the imidazole ring.

Site-specific treatment of the H/D exchange in $\mathrm{HisOMeH}^{+}$ by the two conformation system approach indicates a preference for relative abundances of 0.8 and 0.2 . Conformation $\mathrm{X}$, with an abundance of 0.8 , has three equivalent fast-exchanging sites and one slowly exchanging site, while conformation $\mathrm{Y}$, with an abundance of 0.2 , has two equivalent fast-exchanging sites and two sites that are slower exchanging but with different rates. This view is in agreement with the theoretically obtained structures and ratios, whereby conformation $\mathrm{X}$ corresponds to conformation $\mathrm{HiSOMeH}^{+}$(b) and $\mathrm{Y}$ to $\mathrm{HiSOMeH}^{+}$(c). It should be reiterated that the structures $\mathrm{HisMeOH}^{+}$(a) and $\mathrm{HisMeOH}^{+}$ (b) belong to the same conformation, being practically degenerate in energy, just as in the parent $\mathrm{HisH}^{+}$system. They differ only in the position of the proton, which shuttles between the amino group and the imidazole group.

The lower least-squares sum for the two conformation model means that two different $\mathrm{HisOMeH}^{+}$structures are present in the gas phase. However, the difference in LSS between two models is so small that this conclusion is probably not warranted. Hence it is fair to say that the conformation $\mathrm{HiSOMeH}^{+}$(b) was observed in the H/D exchange experiments.

\section{Concluding Remarks}

The experimental (gas-phase H/D exchange) and theoretical [ab initio G3(MP2)] results described above offer a consistent picture of the gas-phase structure and bonding in protonated histidine and its protonated methyl ester. Important findings can be summarized as follows:

(1) Site-specific gas-phase H/D exchange rate constants of $\mathrm{HisH}^{+}$and $\mathrm{HisOMeH}^{+}$indicate four relatively fast-exchanging and one very slowly exchanging site in the former system and three equivalent fast-exchanging and one slowly exchanging site in the latter species. Three of the four fast $\mathrm{H}$ exchanges in $\mathrm{HisH}^{+}$ are equivalent.

(2) The experimental findings are interpreted by the results of the G3(MP2) calculations. It turns out that the neutral histidine has four conformers/tautomers. The most stable one [His(a)] has two intramolecular HBs: one realized between the carbonyl group and the nitrogen on imidazole ring, whereas the 
second is provided by the HB bridge between the carboxylic group and the $\alpha$-amino group. The protonated histidine has three forms, the most stable one being $\mathrm{HisH}^{+}(\mathrm{a})$, possessing the proton attached to the imidazole ring as customarily assumed. However, the present calculation conclusively shows that the prototropic tautomer $\mathrm{HisH}^{+}$(c) is energetically almost equivalent to $\mathrm{HisH}^{+}$(a). Moreover, credible evidence is provided showing that the hydrogen bond between the $\mathrm{NH}_{2}$ group and the nearest $\mathrm{N}$ atom of imidazole ring is very strong in the protonated species. Taking into account that the transition structure is only $0.3 \mathrm{kcal} \mathrm{mol}^{-1}$ above $\mathrm{HisH}^{+}(\mathrm{a})$, one concludes that the proton moves almost freely between the pyrrolic N(2) nitrogen of the ring and the $\mathrm{N}(1)$ nitrogen of the $\alpha$-amino group. This is a new feature, which was not known in the literature to the best of our knowledge. It is crucial for understanding the measured H/D exchange rates.

The rationalization of the experimental results involve several steps: (i) The fourth nonequivalent fast exchange in $\mathrm{HisH}^{+}$is attributed to the carboxylic groups, since it is missing in $\mathrm{HisOMeH}^{+}$. (ii) Three fast equivalent exchanges are ascribed to the $\mathrm{NH}_{2}$ group, which participates in the strong IHB with the pyrrolic nitrogen of the imidazole group. It is taken for granted that the proton exchange is much faster than H/D exchange. (iii) Finally, a very slow H/D exchange is assigned to a distal N(3) nitrogen atom, which does not participate in the IHB bonding.

(3) Proton affinity of His predicted by the G2(MP2) and G3(MP2) methods is lower than the experimental value ${ }^{19}$ by $3-5$ $\mathrm{kcal} \mathrm{mol}^{-1}$. Hence, additional experimental measurements and highly accurate calculations are highly desirable.

Acknowledgment. We thank the John von Neumann Institut für Computing des Forschungszentrums, Jülich, for allocation of the computing time within the project Computational Study of the Catalytic Triad Active Center in Serine Protease. The collaboration between Zagreb and Madrid research groups is realized through the Cost Action D26/0014/03. Funding by the Ministry of Science, Education and Sports of Republic of Croatia is gratefully acknowledged.

\section{References and Notes}

(1) Harrison, A. G. Mass Spectrom. Rev. 1977, 16, 201. 1203.

(2) Carr, S. R.; Cassady, C. J. J. Am. Soc. Mass Spectrom. 1996, 7,

(3) Bouchoux G.; Buisson, D.-A.; Colas, C.; Sablier, M. Eur. J. Mass Spectrom. 2004, 10, 977.

(4) Hillenkamp, F.; Karas, M.; Beavis, R. C.; Chait, B. T. Anal. Chem. 1991, 63, 1193A.

(5) Fenn, J. B.; Mann, M.; Meng, C. K.; Wong, S. F.; Whitehouse, C. M. Science 1989, 246, 64 .
(6) Green, M. K.; Lebrilla, C. B. Mass Spectrom. Rev. 1997, 16, 53.

(7) He, F.; Marshall, A. G. J. Phys. Chem. A 2000, 104, 562.

(8) Rožman, M.; Kazazić, S.; Klasinc, L.; Srzić, D. Rapid Commun. Mass Spectrom. 2003, 17, 2769.

(9) Dodsan, G.; Wlodamer, A. Trends Biochem. Sci. 1998, 23, 347.

(10) Green, M. K.; Lebrilla, C. B. Int. J. Mass Spectrom. Ion Processes 1998, $175,15$.

(11) Harrison, A. G. Mass Spectrom. Rev. 1997, 16, 201.

(12) Speakman, J. C. J. Chem. Soc. 1949, 3357.

(13) Hadži, D. Pure Appl. Chem. 1965, 11, 435.

(14) Cleland, W. W.; Kreevoy, M. M. Science 1994, 264, 1887.

(15) Frey, P. A.; Whitt, S. A.; Tobin, J. B. Science 1994, 264, 1927.

(16) Warshel, A.; Papazyan, A.; Kollman, P. A. Science 1995, 269, 102.

(17) Shan, Sh. Ou.; Loh, S.; Harschlag, D. Science 1996, 272, 97.

(18) Vianello, R.; Kovačević, B.; Ambrožić, G.; Mavri, J.; Maksić, Z. B. Chem. Phys. Lett. 2004, 400, 117.

(19) Bliznyuk, A. A.; Schaefer, H. F., III; Amster, I. J. J. Am. Chem. Soc. 1993, 115, 5149 .

(20) Maksić, Z. B.; Kovačević, B. Chem. Phys. Lett. 1999, 307, 497.

(21) Bojesan, G.; Breindahl, T. J. Chem. Soc., Perkin Trans. 2 1994, 1029 .

(22) Bouchoux, G.; Salpin, Y. Eur J. Mass Spectrosc. 2003, 9, 39.

(23) Bouchoux, G.; Salpin, Y.; Leblanc, D. Int. J. Mass Spectrom. Ion Processes 1996, 153, 37.

(24) Hunter, E. P. L.; Lias, S. G. J. Phys. Chem. Ref. Data 1998, 27, 413.

(25) Bartmess, J. E.; Georgiadis, R. M. Vacuum 1983, 33, 149.

(26) Frisch, M. J.; Trucks, G. W.; Schlegel, H. B.; Scuseria, G. E.; Robb, M. A.; Cheeseman, J. R.; Zakrzewski, V. G.; Montgomery, J. A., Jr.; Stratmann, R. E.; Burant, J. C.; Dapprich, S.; Millam, J. M.; Daniels, A D.; Kudin, K. N.; Strain, M. C.; Farkas, O.; Tomasi, J.; Barone, V.; Cossi, M.; Cammi, R.; Mennucci, B.; Pomelli, C.; Adamo, C.; Clifford, S.; Ochterski, J.; Petersson, G. A.; Ayala, P. Y.; Cui, Q.; Morokuma, K.; Malick, D. K.; Rabuck, A. D.; Raghavachari, K.; Foresman, J. B.; Cioslowski, J.; Ortiz, J. V.; Baboul, A. G.; Stefanov, B. B.; Liu, G.; Liashenko, A.; Piskorz, P.; Komaromi, I.; Gomperts, R.; Martin, R. L.; Fox, D. J.; Keith, T.; AlLaham, M. A.; Peng, C. Y.; Nanayakkara, A.; Gonzalez, C.; Challacombe, M.; Gill, P. M. W.; Johnson, B. G.; Chen, W.; Wong, M. W.; Andres, J. L.; Head-Gordon, M.; Replogle, E. S.; Pople, J. A. GAUSSIAN 98 (Revision A.10); Gaussian, Inc.: Pittsburgh, PA, 1998.

(27) Koch, W.; Holthausen, M. C. A Chemist's Guide to Density Functional Theory; Wiley-VCH: Weinheim, Germany, 2000.

(28) Becke, A. D. J. Chem. Phys. 1993, 98, 1372.

(29) Lee, C.; Yang, W.; Parr, R. G. Phys. Rev. B 1988, 37, 785.

(30) For critical review of the performance of various theoretical methods, see Alcami, M.; Mó, O.; Yàñez, M. Mass Spectrom. Rev. 2001 20, 195 .

(31) Sun, W.; Kinsel, G. R.; Marynick, D. S. J. Phys. Chem A 1999 $103,4113$.

(32) Bader, R. F. W. Atoms in molecules. A quantum theory; Clarendon Press: Oxford, U.K., 1990

(33) Sanz, P.; Mó, O.; Yáñez, M. Phys. Chem. Chem. Phys. 2003, 5, 2942.

(34) (a) George, P.; Trachtman, M.; Brett, A. M.; Bock. C. W. J. Chem. Soc., Perkin Trans 2 1977, 1036. (b) George, P.; Bock, C. W.; Trachtman, M. J. Chem. Educ. 1984, 61, 225.

(35) Howard, S. T. J. Am. Chem. Soc. 2000, 122, 8238.

(36) Stare, J.; Mavri, J.; Ambrožić, G.; Hadži, D. THEOCHEM 2000, 500,429 . 